\title{
Determinants of Entrepreneurial Expansion and Sustainability Among MSEs in Wolaita and Dawro Zones, Ethiopia
}

\author{
Alemayehu Elda Ergo*, Shemilis Tamirat Woldekidan \\ Department of Management, College of Business and Economics, Wolaita Sodo University, Wolaita Sodo, Ethiopia \\ Email address: \\ alemayehu.elda $a$ yahoo.com (A. E. Ergo), sdawro $a$ yahoo.com(S. T. Woldekidan) \\ ${ }^{*}$ Corresponding author
}

\section{To cite this article:}

Alemayehu Elda Ergo, Shemilis Tamirat Woldekidan. Determinants of Entrepreneurial Expansion and Sustainability Among MSEs in Wolaita and Dawro Zones, Ethiopia. International Journal of Business and Economics Research. Vol. 7, No. 5, 2018, pp. 126-135. doi: 10.11648/j.ijber.20180705.11

Received: June 6, 2018; Accepted: August 9, 2018; Published: September 4, 2018

\begin{abstract}
The future of the Ethiopian economy in the urban area depends to a great degree on the success of Micro and Small enterprises (MSEs) as in many other developing countries since MSEs are important to economic growth and considerably essential to generate employment. However, Ethiopian MSEs are facing a series impediments emanating from external and internal factors that have sign if I can't adverse effects on their performance, growth and sustainability. The purposes of this research are to explicitly enquiry and consider aspects that are hampering the performance, growth and sustainability of MSEs in Wolaita and Dawro Zones. The study was utilized causal research design to achieve the research objectives. The target population under study is all enterprises in the five developmental sectors in five towns from both Wolita and Dawuro zone Administrations. The study was conducted between June 2016 March 2017. In this study, primary and secondary data types and sources were used. The instruments to collect primary data were questionnaires. Sample size was 347 which determined by using Yamane (1967) formula and individual informants were selected via stratified random sampling technique. The data collected was analyzed quantitatively and qualitatively by the aid of Spss. V.16. The finding of the study showed that the variables (financial, marketing, working premises, technological, political-legal, entrepreneurial and managerial factors affecting enturprenual growth and sustainability both in Wolaita and Dawuro zones which were explained the variance of $34 \%$ and $66 \%$ of the variance was explained by other factors which are not the part of this study variables.
\end{abstract}

Keywords: MSEs, Internal and External Determinants, Expansion and Sustainability

\section{Introduction}

The micro and small enterprise sector recognized as an integral component of economic development throughout the world. At this moment the importance and contribution of micro and small enterprises (here after MSEs) in stimulating development hence growth is almost acknowledged particularly in those of developing countries of Asia, Latin America and Africa. Throughout the world, governments have acknowledged the impact of small and micro enterprises (MSEs) on job creation, improvement of people's standards of living and hence an overall impact on the economy [1]. According to similar study done in Mekele [2], MSEs have been the primary sources of employment creation not only in developing countries but also in developed countries. In developing countries, MSEs have also a crucial role because of their potential contributions to improvement of income distribution, employment creation, poverty reduction, industrial development, rural development, and export growth. This also contended that the dynamic role of micro and small enterprises (MSEs) in developing countries as engines through which the growth objectives of developing countries can be achieved has long been recognized. He cited earlier empirical findings for that the estimated employment of micro and small enterprises is $22 \%$ of the adult population in developing countries. In developing countries, micro and small enterprises by virtue of their size, capital investment and their capacity to generate greater employment, have 
demonstrated their powerful effect for rapid economic growth[1].

According to MSEs Development Strategy of Ethiopia, the sector is crucially important to the economic and social development of the country in the sense that it generates broader job opportunities and assist to alleviate poverty and facilitates rural and urban economic linkage, boost the economy as well as promotes entrepreneurship culture, enhance self-employment, serves as fertile ground for the emerging of medium and large industries and know a days the MSEs development was integrated in the GTP 1 as one of the pillars of the industrial development and taken as one of the best tools to implement the country's industrial development strategy. It is also believed to control the effects of unemployment and urban poverty [3].

Despite MSEs vital role in job creation and poverty reduction their growth and sustainability is constrained by several factors. Factors affecting the micro and small enterprises growth and sustainability have been a well research area by scholars for many years. Previous research indicates that several factors influence MSEs growth and sustainability includes among many others: contextual factors, management constraints, MSEs professional background, entrepreneurship capabilities and preferences, as well as the technology and micro environment [4].

Poor management and accounting practices have hampered the ability of smaller enterprises to raise finance. Information asymmetries associated with lending to small scale borrowers have restricted the flow of finance to smaller enterprises. In spite of these claims however, some studies show a large number of small enterprises fail because of non-financial reasons [5]. Regardless of the high failure rate by MSEs in Kenya, their enormous contribution to the entire economy cannot be overlooked [6].

Empirical studies conducted in sub-Saharan Africa suggest a wide array of problems in the ways markets work, which prevent prospective entrepreneurs from joining the MSEs sector, and more importantly, which precludes the graduation of MSEs into medium-sized firms. More often, lack of adequate credit for setting up new enterprises, imperfect contract enforcement, and high transaction costs between assemblers and parts suppliers, and between traders and producers are prohibitively high in developing countries. The presence of such types of market failures would significantly reduce the number of MSEs that would be established in the economy and, hence the labor absorptive capacity of the sector.

Micro and small enterprise in Ethiopia are, confronted with several factors that affect the growth and sustainability of MSE. Despite the critical role played by the small enterprise sector, it is faced with numerous challenges and constraints. The major factors include financial problems, lack of qualified employees, lack of proper financial records, marketing problems and lack of work premises, etc. Besides, environmental factor affects the business which includes social, economic, cultural, political, legal and technological factors. In addition there are also personal attitudes or internal factors that affect the growth and sustainability of
MSE, which are related to the person's individual attitude, training and technical know-how. Generally, there are external and internal factors which are significantly affecting the growth and sustainability of MSEs in both of the zones that underlies the motivation of the researchers to thoroughly investigate the factors and their bearings on the growth and sustainability and sustainability.

\subsection{Statement of the Problem}

Smaller businesses were once regarded as basis for a country's economic development, poverty reduction, creating employment opportunity etc. MSEs have great contribution; for example, according to some researchers view, this sector generate 6.2 percent of the aggregate employment in United State, 22.3 percent in China, about 80 percent in India, 67 percent in Japan, about 70 percent in European Union countries and in Brazilian economy 20 percent of the total gross production and 3 percent of the total export is the share of micro and small enterprise. Despite their significance, recent studies show that micro and small enterprise fail within the first few years of operation. Researchers in area of MSEs sustainability issues argued that in most developing countries and highlighted the constraints faced by MSEs both at start up phases and after their establishment, in Africa. For instance, according to the failure rate of MSEs is $85 \%$ out of 100 enterprises due to lack of skills and access to capital [1]. Similarly, several researches have been shown that this sector faced different problems and constraints. As suggested by [7], the contextual, institutional, infrastructure constraints, corruption, finance and marketing constraints are the most common challenges that hold back the growth of micro and small enterprises.

The ever changing business environment requires firms to adapt quickly to associated new challenges and competition, and presents particular problems for small businesses given their small size and limited resources. Research undertaken in Kenya, Nairobi suggests that the Small businesses increasingly face competition not only from their peers but also from large corporations participating in niche markets. Moreover, it is typical problem of African MSEs to be lacking in business skills and collateral to meet the existing lending criteria of financial institutions. Ethiopian MSEs are able to source and obtain finance mostly from informal sectors like friends, 'Idir' 'Iqub' and relatives while medium or large enterprises obtain funds from banks. This unequal access to finance by MSEs and medium and large enterprises has undermined the role of MSEs in the economic development in most African countries [8].

Recent studies on MSEs indicated that MSEs in Ethiopia are confronted by many problems. The identified constraints facing MSEs in Ethiopia like most developing economies include unfavorable legal and regulatory environment such as discriminatory regulatory practices; lack of access to markets, finance, business information; lack of working and/or business premises at affordable rent; low ability to acquire skills and managerial expertise; low access to appropriate technology; and poor access to quality business infrastructure. 
The problem of raw material shortages, lack of working capital and effective marketing practices faced by micro and small manufacturing industries jeopardize their sustainability or threatening the existence and continuity of business operation[9].

In Wolaita and Dawuro Zones, MSEs have faced a number of problems. Unlike the major cities in the country, entrepreneurial sustainability and growth and sustainability related problems in the study area were not scholarly uncovered using scientific researches. This study is therefore seeks to provide a holistic and genuine analysis of factors affecting the sustainability and growth and sustainability of MSEs through a comprehensive review of literature and empirical study available on the MSEs area. This can be result in the development of a theoretical framework for the initiation of policies and feasible projects to improve institutional supports and favorable business environment in Ethiopia in general and Wolaita and Dawuro zones in particular.

\subsection{Research Hypothesis}

To develop a research hypothesis, a deep previous research reading is vital. With the help of sufficient and appropriate previous research study, the key study variables can be identified and the research hypothesis is formulated. The literatures on the factors affecting the growth and sustainability of MSEs and the study will tests the following five hypotheses to achieve the research objectives.

$\mathrm{Ho}_{1 \text { : }}$ Financial factors have a significant impact on the growth and sustainability of MSEs in Wolaita and Dawuro zones.

$\mathrm{Ho}_{2}$ : Marketing Factors has a significant impact on the growth and sustainability of MSEs in Wolaita and Dawuro zones.

$\mathrm{Ho}_{3}$ : Working premises factors have a significant impact on the growth and sustainability of MSEs in Wolaita and Dawuro zones.

$\mathrm{Ho}_{4}$ : Economic infrastructure base has a significant impact on the growth and sustainability of MSEs in Wolaita and Dawuro zones.

$\mathrm{Ho}_{5}$ : managerial factors have a significant impact on the growth and sustainability of MSEs in Wolaita and Dawuro zones.

$H_{6}$ : Entrepreneurial factors have a significant impact on the growth and sustainability of MSEs in Wolaita and Dawuro zones

$\mathrm{HO}_{7}$ : Political - legal factors have a significant impact on the growth and sustainability of MSEs in Wolaita and Dawuro zones

$\mathrm{Ho}_{8}$ : Technological factors have a significant impact on the growth and sustainability of MSEs in Wolaita and Dawuro zones

\subsection{Objectives of the Study}

\subsubsection{General Objective}

The main objective of the study is to investigate the internal and external factors that are significantly affecting the growth and sustainability (entrepreneurial endeavors) of MSEs in Wolaita and Dawro Zones.

\subsubsection{Specific Objectives}

1. To assess the internal obstacles those are deterring the growth and sustainability of MSEs in the Wolaita and Dawuro zones.

2. To examine the major external impediments to MSEs Growth and sustainability in Wolaita and Dawuro zones.

Conceptual Frame work of the study

Building a conceptual model is done on the basis of theoretical knowledge of the MSEs growth and sustainability affecting factors, the nature, its properties and the interrelationships should be identified and structured in to a framework. This conceptual model gives an exact idea of the research problem and shows its various properties and variables to be studied. Since MSEs growth and sustainability is influenced by both internal and contextual factors, These factors are divided into two group's internal and external factors. The internal factors are those that originate within the institution. To organize in a line the conceptual framework with the research objectives, MSEs growth and sustainability is the dependent variable and hampering factors will be independent variables. The relationship can be expressed and shown in the Figure 1 below.

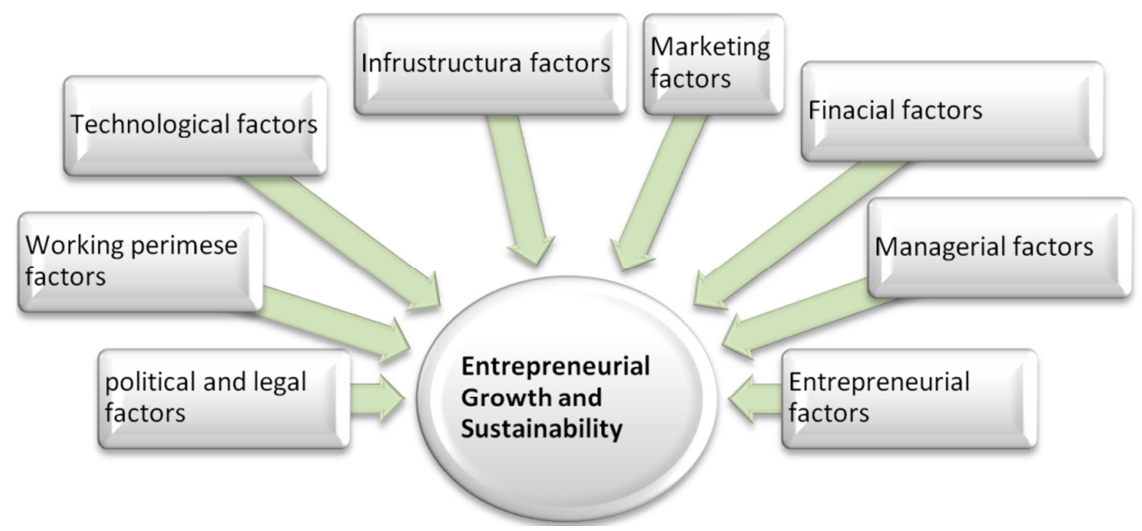

Figure 1. Conceptual frame works (researcher's own model). 


\section{Data and Methodology}

\subsection{Research Design}

The research design that would be employed under this study was causal. The major purpose of the casual research design is it concerned with specifying and interpreting relationships between predictor variables, the relationship between outcome variables would be correlated with an aim of estimating the integrated influence of the factors on growth and sustainability of MSEs in two zones Moreover the data were described, correlated and finally predictions were made to the combined effect of internal and external obstacles that hinder the growth and sustainability of MSEs in Wolaita and Dawro zones.

\subsection{Sampling Procedures}

\subsubsection{The Population of Study}

The target population consists of the MSEs registered enterprises in the past five Ethiopian fiscal years operating their business in all of the five developmental sectors in Sodo, Areka and Bodit towns from Wolaita zone and Tarcha and Lomma towns from Dawro zone. The registered enterprises could be obtained from the records of Wolaita and Dawro zones' trade and industry departments.

\subsubsection{Sampling Technique}

This study was employed a stratified random sampling technique; sampling frames were enterprises in five development oriented MSEs such as manufacturing, construction, retail, service and urban agriculture. This technique was preferred because sampling frame would be organized into relatively homogeneous groups or strata before selecting elements for the sample. In each strata element there are heterogeneous groups. This step increases the probability that the final sample would be representative in terms of the stratified groups.

\subsubsection{Sample Size}

This study applied a simplified sample size determination formula provided by Yamane (1967) in order to determine the required sample size at $95 \%$ confidence with the level of precision 5\% [10]. This sample size determination method is more applicable when the sampling population is known and finite and it is also statistically permutable to commit 0.01 to 0.1 level of bias in study process and to determine the required sample size the following Yamane formula applied in this study below:-

$$
n=\frac{N}{1+N(e)^{2}}
$$

Therefore, the sample size of this study will be

$$
\mathrm{n}=\frac{N}{1+N(e) 2}=\frac{2638}{1+2638(5 \%) 2}=\frac{2638}{7.595}
$$

$\mathrm{n}=347$

Where

i. $\quad n-$ is the sample size, $=347$

ii. $\mathrm{N}$ - is the population size, $=2638$

iii. $\mathrm{e}$ - is the level of precision(sampling error) $=5 \%$

Hence, the sample size of the study is 347 as shown in the following table.

\begin{tabular}{|c|c|c|c|c|c|c|c|c|}
\hline Total & Enterprise & & & & Deter & d San & & \\
\hline No & Sub sectors & w. Sodo & Dawuro & Total & $\mathbf{W} / \mathbf{Z}$ & $D / Z$ & $\begin{array}{l}\text { Total } \\
\text { Total }\end{array}$ & $\%$ \\
\hline 1 & Construction & 699 & 37 & 736 & 92 & 5 & 97 & 27.9 \\
\hline 2 & Manufacturing & 276 & 58 & 334 & 36 & 8 & 44 & 12.7 \\
\hline 3 & Urban Agri. & 148 & 59 & 207 & 19 & 8 & 27 & 7.8 \\
\hline 4 & Retail Business & 415 & 257 & 672 & 54 & 34 & 88 & 25.5 \\
\hline 5 & Service & 574 & 115 & 689 & 76 & 15 & 91 & 26.1 \\
\hline Total & & 2112 & 526 & 2638 & 278 & 69 & 347 & 100 \\
\hline
\end{tabular}

Table 1. Trade and industry department of wolaita and Dawro zone.

NB: By using stratified proportionate random sampling

\subsection{Data Sources}

\subsubsection{Primary Data Sources}

In order to realize the target, the study used well-designed questionnaire as best instrument. This was completed by the owner managers/or operators of the enterprises.

\subsubsection{Secondary Data Sources}

Secondary data from office manuals, circulars and policy documents used to provide additional information where appropriate. Besides, variety of books, published government documents, and reports reviewed to make the study fruitful.

\subsection{Data collection Instruments}

\section{Questionnaire}

Questionnaires were e prepared to collect the required data from MSEs in the study area. The layout of the questionnaire was kept very simple to encourage meaningful participation by the respondents. Five point Likert scale questionnaires were designed and used to examine how strongly operators agree or disagree with the statements on a five point scale. The type of scales used to measure the items on the instrument is continuous scales (strongly agree to strongly disagree). 


\subsection{Data Processing and Analysis}

\subsubsection{Data Processing}

In the data processing procedures like editing, coding, classification and tabulation of the collected data was used. Data processing has two phases namely: data clean-up and data reduction. During data clean-up the collected raw data could be edited to detect anomalies, errors and omissions in responses and checking that the questions are answered accurately and uniformly.

\subsubsection{Data Analysis}

This will be the further transformation of the processed data to look for patterns and relationship between and/or among data groups by using descriptive and inferential statistical analysis. To evaluate the effects of various internal and external factors on the growth and sustainability of micro and small enterprises, simple descriptive statistics and advanced statistical models (Pearson linear correlations and multiple regressions) was e used with the help of statistical package for social sciences (SPSS) version 20 software. To know the impact and relationship of independent variables on the dependent variable (growth and sustainability), the regression function can be:-

$$
\mathrm{Y}=\mathrm{a}+\mathrm{b}_{1} \mathrm{x}_{1}+\mathrm{b}_{2} \mathrm{x}_{2}+\mathrm{b}_{3} \mathrm{x}_{3}+\mathrm{b}_{4} \mathrm{x}_{4}+\mathrm{b}_{5} \mathrm{x}_{5}+\mathrm{b}_{6} \mathrm{x}_{6}+\mathrm{b}_{7} \mathrm{x}_{7}+\mathrm{b}_{8} \mathrm{x}_{8}
$$

\section{Where}

$a=$ base constant $b_{1}-b_{8}=$ regression coefficients of $X_{1} \ldots X_{8}$ with each independent variable which measures the change in the mean value of $\mathrm{Y}$, per unit change in their respective independent variables. $\mathrm{Y}$ is the response or dependent variable $\mathrm{X}_{1-8}=$ internal and external factors

\subsection{Pilot Testing (Validity and Reliability)}

Pilot study was conducted to refine the methodology and test instrument such as a questionnaire before administering the final phase. A questionnaire was tested on potential respondents to make the data collecting instruments objective, relevant, suitable to the problem and reliable. Whenever a test or other measuring device is used as part of the data collection process, the validity and reliability of that test is important. Validity is the extent to which a test measures what it is supposed to measure. Reliability is the degree to which a test consistently measures whatever it measures.

\section{Reliability of the Instruments}

The researcher were selected a pilot group of 34 individuals from the target population to test the reliability of the research instrument. The aim is to correct inconsistencies arising from the instruments, which ensure that they measure what is intended. After piloting the researchers had made some amendments' on questionnaires. In this study each statement rated on a five point likert response scale which includes strongly agree, agree, undecided, disagree and strongly disagree. Based on this an internal consistency reliability test was conducted in Sodo, Areka and Boditi towns of Wolaita Zone with a sample of 34 operators and the
Cronbach's alpha coefficient for the instrument was found as 0.722 which is reliable. Typically an alpha value of 0.70 or higher is taken as a good indication of reliability.

\section{Results}

\subsection{General Back Ground of the Respondents}

This implies that the general background information of the study respondents.

Table 2. Age, Sex and Marital status of the respondents.

\begin{tabular}{llll}
\hline & Category & Frequency & Percent \\
\hline & $18-35$ & 9 & 2.62 \\
Age category of & $35-50$ & 264 & 76.74 \\
respondents & $50-64$ & 69 & 20.06 \\
& $>64$ & 2 & 0.58 \\
& Total & 344 & 100.0 \\
& Male & 225 & 66.37 \\
Sex of the respondents & Female & 114 & 33.63 \\
& Total & 339 & 100.0 \\
& Marred & 88 & 26.43 \\
Marital statusof the & Unmarried & 242 & 72.67 \\
respondents & Divorced & 2 & 0.6 \\
& Withdrawal & 1 & 0.3 \\
& Total & 333 & 100.0 \\
\hline
\end{tabular}

Source: field survey 2017

The above table 2 gives the clue about the age of respondents from the 333 respondents, $76.74 \%$ were under age group of $35-50$ years, $20.06 \%$ were under age group of 50-64 years and others constituted 3.2\%. From the above table information, the researchers concluded that the strategy of MSE in Ethiopia designed and targeted the youths and to reduce their unemployment problems. But the study area zones sample respondent responses showed that only $2.62 \%$ were lies under youth age category and more than $95 \%$ of respondent's age lies between 35-64 years.

The above table 2 also showed that the $66.37 \%$ of respondents were male and $33.63 \%$ were female and this shows that there was good and promising women entrepreneurs' participation in the study area. The above table 4.2.1 also showed the marital status of the respondents. From the 333 sample respondents, $72.67 \%$ were unmarried and $26.43 \%$ were married. Both divorced and withdrawal constitutes $0.9 \%$ Among 338 sample respondents, $34.32 \%$ were completed secondary school, $21.6 \%$ were primary school, $15.38 \%$ were Technical and vocational school graduates, $12.43 \%$ were diploma holders, $7.99 \%$ were first degree graduates and $6.8 \%$ were only read and write. The percentage of graduates from higher institutions was low and the researchers concluded that the higher institution graduates were interested to join in MSE sector because of their attitude towards MSE sector. So continuous training and attitude changing activities should be important. 


\subsection{Correlation and Multiple Regressions Analysis}

In this section, the results of inferential statistics are presented. For the purpose of assessing the objectives of the study, Pearson's Product Moment Correlation Coefficient and regression analysis were performed. With the aid of these statistical techniques, conclusions are drawn with regard to the sample and decisions are made with respect to the research hypothesis.

\subsubsection{Pearson's Product Moment Correlation Coefficient}

In this study Pearson's Product Moment Correlation
Coefficient was used to determine whether there is significant relationship between financial, working places, infrastructure marketing, technological political-legal, entrepreneurial and managerial factor with MSE growth and sustainability. The below table 3 presents the results of Pearson's Product Moment Correlation on the relationship between independent variables and dependent variable. It also indicates that the Correlation coefficients for the relationships between growth and sustainability and its independent variables are linear and positive ranging from weak relation to substantial.

Table 3. The relationship between MSEs growth and sustainability and affecting factors.

\begin{tabular}{|c|c|c|}
\hline Affecting factors & Correlations, probability values and sample size & $\begin{array}{l}\text { Entrepreneurial Growth and Sustainability(value } \\
\text { of Correlations, probabilities and sample size) }\end{array}$ \\
\hline \multirow{3}{*}{$\begin{array}{l}\text { Entrepreneurial Growth and } \\
\text { Sustainability(dependent variable) }\end{array}$} & Pearson Correlation & 1 \\
\hline & P. value & 000 \\
\hline & $\mathrm{N}$ & 343 \\
\hline \multirow{4}{*}{ Political - legal factors $\left(\mathrm{x}_{1}\right)$} & Pearson Correlation &.-320 \\
\hline & P. value & 000 \\
\hline & $\mathrm{N}$ & 343 \\
\hline & Pearson Correlation & -.337 \\
\hline \multirow[t]{3}{*}{ Working premise factors $\left(\mathrm{x}_{2}\right)$} & P. value & 000 \\
\hline & $\mathrm{N}$ & 342 \\
\hline & Pearson Correlation &.-253 \\
\hline \multirow[t]{3}{*}{ Technological factors $\left(\mathrm{x}_{3}\right)$} & P. value & 000 \\
\hline & $\mathrm{N}$ & 343 \\
\hline & Pearson Correlation & .040 \\
\hline \multirow[t]{3}{*}{ Infrastructural factors $\left(\mathrm{x}_{4}\right)$} & P. value & 0.229 \\
\hline & $\mathrm{N}$ & 343 \\
\hline & Pearson Correlation & -.479 \\
\hline \multirow{3}{*}{ Marketing factors $\left(\mathrm{x}_{5}\right)$} & P. value & 000 \\
\hline & $\mathrm{N}$ & 343 \\
\hline & Pearson Correlation & -.373 \\
\hline \multirow[t]{3}{*}{ Financial factors $\left(\mathrm{x}_{6}\right)$} & P. value & 000 \\
\hline & $\mathrm{N}$ & 343 \\
\hline & Pearson Correlation & -.362 \\
\hline \multirow[t]{3}{*}{ Managerial factors $\left(\mathrm{x}_{7}\right)$} & P. value & 000 \\
\hline & $\mathrm{N}$ & 343 \\
\hline & Pearson Correlation & -.446 \\
\hline \multirow[t]{2}{*}{ Entrepreneurial factors $\left(\mathrm{x}_{8}\right)$} & P. value & 000 \\
\hline & $\mathrm{N}$ & 342 \\
\hline
\end{tabular}

Source: the field data $(2017)^{* *}$. Correlation is significant at the 0.01 level (1-tailed)

The above table3provides a matrix of the correlation coefficients for the dependent and independent variables (correlation direction, strength and significance). Each variable is perfectly correlated with itself and so correlation $=1$ along the diagonal of the table. The findings indicated that Political - legal factors was significantly associated with entrepreneurial growth and sustainability $(\mathrm{r}=-320, \mathrm{P}<0.05)$ implies that an increase in political and legal factors constraint results in a decrease in entrepreneurial growth and sustainability. Association between working premise factors and entrepreneurial growth and sustainability $(\mathrm{r}=-0.337, \mathrm{P}<0.05)$, implies that an increase in Working premise constraint results in a decrease in entrepreneurial growth and sustainability. The Association between technological factors and entrepreneurial growth and sustainability $(\mathrm{r}=-0.253, \mathrm{P}<0.05)$, implies that an increase in technological constraint results in a decrease in entrepreneurial growth and sustainability and the relationship is weak.
Association of infrastructural factors with entrepreneurial growth and sustainability is $(r=-0.040, \mathrm{P}<0.05)$ which is weak and it implies that an increase in infrastructural constraint results in a decrease in entrepreneurial growth and sustainability. Findings also indicated the association between marketing factors and entrepreneurial growth and sustainability is moderate, $(\mathrm{r}=-.479, \mathrm{P}<0.05)$. which implies that an increase in marketing constraint results in a decrease in entrepreneurial growth and sustainability. Findings also indicated the association between financial factors and entrepreneurial growth and sustainability is weak, $(\mathrm{r}=.-.373, \mathrm{P}<0.05)$ which implies that an increase in financial constraint results in a decrease in entrepreneurial growth and sustainability. Association of managerial factors with entrepreneurial growth and sustainability is $(r=-.362$, $\mathrm{P}<0.05$ ) which is weak and it implies that an increase in internal managerial constraint results in a decrease in entrepreneurial growth and sustainability. Findings also indicated that the 
association between entrepreneurial factors and entrepreneurial growth and sustainability is moderate, $(\mathrm{r}=.446, \mathrm{P}<0.05)$. which implies that an increase in entrepreneurial constraint results in a decrease in entrepreneurial growth and sustainability.

\subsubsection{Correlation Coefficient Squared $\left(\boldsymbol{R}^{2}\right)$}

The correlation coefficient squared (known as the coefficient of determination, $R^{2}$ ) is a measure of the amount of variability in one variable that is shared by the other.

Table 4. Correlation coefficient squared of dependent and independent variables.

\begin{tabular}{|c|c|c|c|c|}
\hline No & Constraints & Correlation & $\begin{array}{l}\text { correlation coefficient } \\
\text { squared }\left(\mathbf{R}^{2}\right)\end{array}$ & $\begin{array}{l}\text { Extent of entrepreneurial growth and sustainability } \\
\text { affecting variance shared by each factor }\end{array}$ \\
\hline 1 & Political and legal factors & -0.320 & 0.1024 & 10.24 \\
\hline 2 & Working premise factors & -0.337 & 0.1136 & 11.36 \\
\hline 3 & Technological factors & -0.253 & 0.0640 & 6.4 \\
\hline 4 & Infrastructural factors & -0.040 & 0.0016 & 0.16 \\
\hline 5 & Marketing factors & -0.479 & 0.2294 & 22.94 \\
\hline 6 & Financial factors & -0.373 & 0.1391 & 13.91 \\
\hline 8 & Entrepreneurial factors & -0.446 & 0.1989 & 19.89 \\
\hline
\end{tabular}

Source:-( Field data 2017)

Really the entrepreneurial growth and sustainability are varies from enterprise to enterprise because of any number of factors (different ability, different levels of working and so on). $R^{2}$ to show that how much of this variability is shared by each factor. Marketing constrain shared $22.94 \%$ of entrepreneurial growth and sustainability constraints variances. Entrepreneurial factors shares $19.89 \%$ of entrepreneurial growth and sustainability constraints variances, Financial factors shares $13.91 \%$, Managerial factors shares $13.10 \%$ working place factors shares $11.36 \%$,
Political and legal factors share 10.24, technological constraints shares $6.4 \%$ and infrastructure factor shares $0.16 \%$ entrepreneurial growth and sustainability constraints variances respectively.

\subsubsection{Multiple Regression Analysis}

Multiple regressions is a logical extension of these principles to situations in which there are predictors and each predictor variable has its own coefficient, and the outcome variable is predicted

Table 5. Multiple regressions Summary.

\begin{tabular}{|c|c|c|c|c|c|c|c|c|c|c|}
\hline \multicolumn{11}{|c|}{ Model Summary } \\
\hline \multirow{2}{*}{ Model } & \multirow{2}{*}{$\mathbf{R}$} & \multirow{2}{*}{ R Square } & \multirow{2}{*}{$\begin{array}{l}\text { Adjusted R } \\
\text { Square }\end{array}$} & \multirow{2}{*}{$\begin{array}{l}\text { Std. Error of the } \\
\text { Estimate }\end{array}$} & \multicolumn{5}{|l|}{ Change Statistics } & \multirow{2}{*}{$\begin{array}{l}\text { Durbin- } \\
\text { Watson }\end{array}$} \\
\hline & & & & & R Square Change & F Change & df1 & df2 & Sig. F Change & \\
\hline 1 & $.583^{\mathrm{a}}$ & .340 & .324 & .699 & .340 & 21.389 & 8 & 332 & .000 & 1.484 \\
\hline
\end{tabular}

a. Predictors: (Constant), X8, X4, X1, X2, X3, X5, X6, X7

b. Dependent Variable: Y

The regression summary model indicated that the coefficient(R) with a value of 0.583 and co-efficient of determination $\left(\mathrm{R}^{2}\right)$ with the value of 0.340 or $34 \%$ confirms that the identified MSEs growth and sustainability hampering factors attributes $34 \%$ while the remaining 66 percent could be explained by other MSEs growth and sustainability influencing factors which did not included in this study. To conclude that, among eight identified study variables, five (financial, marketing, working place, entrepreneurial and infrastructural) are statistically significant $(\mathrm{p}<0.05)$ while the remaining three variables (managerial, technological and political-legal) factors were not statistically significant because of their $p$-value is greater than predetermined level ( $\mathrm{p}>0.05)$.

\subsubsection{One Way ANOVA (Analysis of Variance)}

The study further used one way Analysis of Variance (ANOVA) in order to test the significance of the overall regression model.

Table 6. One way ANOVA (analysis of variance).

\begin{tabular}{|c|c|c|c|c|c|c|}
\hline \multicolumn{7}{|c|}{ ANOVA $^{b}$} \\
\hline & & Sum of Squares & Df & Mean Square & $\mathbf{F}$ & Sig. \\
\hline \multirow{3}{*}{1} & Regression & 83.591 & 8 & \multirow{3}{*}{$\begin{array}{l}10.449 \\
.489\end{array}$} & \multirow[t]{3}{*}{21.389} & \multirow[t]{3}{*}{$.000^{\mathrm{a}}$} \\
\hline & Residual & 162.187 & 332 & & & \\
\hline & Total & 245.778 & 340 & & & \\
\hline
\end{tabular}

a. Predictors: (Constant), financial, marketing, working place, entrepreneurial and infrastructural, managerial, technological and political-legal)

b. Dependent Variable: Entrepreneurial growth and sustainability.

Table 6 hence shown the regression and residual (or error) sums of squares. The variance of the residuals (or errors) is the value of the mean square which is 10.449 . The predictors $\mathrm{X}_{1}$ up to $\mathrm{X}_{8}$ (financial, marketing, working place, entrepreneurial and infrastructural, managerial, technological and political-legal) represent the independent variables as the major factors determining MSEs growth and sustainability. The results of ANOVA test which reveal that the eight 
independent variables notably; have a significance influence on MSEs growth and sustainability. Since the $\mathrm{P}$ value is actual 0.00 which is less than $5 \%$ level of significance is large enough to conclude that the financial, marketing, working place, entrepreneurial and infrastructural, managerial, technological and political-legal significantly determine MSEs growth and sustainability in the Wolita Zone and Dawuro Zone.

\subsubsection{Coefficients of Multiple Regressions}

Table 7. Predicting MSEs Growth and sustainability by using Coefficients of regression.

\begin{tabular}{|c|c|c|c|c|c|c|c|c|}
\hline \multicolumn{7}{|c|}{ Coefficients } & \multirow{2}{*}{\multicolumn{2}{|c|}{ Co linearity Statistics }} \\
\hline \multirow{2}{*}{\multicolumn{2}{|c|}{ Model }} & \multicolumn{2}{|c|}{$\begin{array}{l}\text { Unstandardized } \\
\text { Coefficients }\end{array}$} & \multirow{2}{*}{$\begin{array}{l}\text { Standardized } \\
\text { Coefficients } \\
\text { Beta }\end{array}$} & \multirow[t]{2}{*}{$\mathbf{T}$} & \multirow[t]{2}{*}{ Sig. } & & \\
\hline & & B & Std. Error & & & & tolerance & VIF \\
\hline \multirow{8}{*}{1} & (Constant) & 5.330 & .190 & & 28.008 & $0.000 * *$ & & \\
\hline & Political-legal factors (x1) & -.040 & .060 & -.037 & -0.677 & 0.499 & .674 & 1.483 \\
\hline & Working premise factors $(\mathrm{x} 2)$ & -.147 & .045 & -.184 & -3.239 & $0.001 * *$ & .616 & 1.623 \\
\hline & Technological factors (x3) & -.013 & .045 & -.017 & -0.302 & 0.763 & .640 & 1.563 \\
\hline & Marketing factors (x5) & -.414 & .078 & -.323 & -5.329 & $0.000 * *$ & .542 & 1.844 \\
\hline & Financial factors $(\mathrm{x} 6)$ & -.135 & .060 & -.137 & -2.251 & $0.025 * *$ & .536 & 1.864 \\
\hline & Managerial factors(x7) & .063 & .080 & .060 & 0.789 & 0.430 & .347 & 2.885 \\
\hline & Entrepreneurial factors (x8) & -.184 & .068 & -.192 & -2.697 & $0.007 * *$ & .391 & 2.560 \\
\hline
\end{tabular}

Dependent variable:-Growth and sustainability Source: - Field survey

As indicated in the above table7, the Sig -value proves or disproves the significance of the impact. A Sig -value is said to be significant if it is less than the level of significance, (5\%). If the Sig-value is considered significant (is less than the specified level of significance), and the null hypothesis is false, otherwise it become true. To make the discussion on the previously formulated hypothesis, the above table is used to decide on it.

In table the regression model above has established that taking eight independent variables into account notably; $\mathrm{X}_{1}$ $\mathrm{X}_{8}$ constant at Zero influences, MSEs growth and sustainability will be (5.330). The results presented also shows that taking all other independent variables at zero, a unit increase in $\mathrm{X}_{1 \text { (political-legal) }}$ leads to a 0.040decreasein MSEs growth and sustainability; a unit increase in $\mathrm{X}_{2}$ (working premises) leads to 0.147 decreasein MSEs performance; and a unit increase in $\mathrm{x}_{3}$ (technological) leads to 0.013 decrease in MSES growth and sustainability. a unit increase in $\mathrm{X}_{4 \text { (infrastructural }}$ factors) leads to a 0.136decreasein MSEs performance; a unit increase in $\mathrm{X}_{5 \text { (marketing factor constraint) }}$ leads to 0.414 decreasein MSEs performance; a unit increase in $\mathrm{x}_{6 \text { (financial constraints) }}$ leads to 0.135 decreasein MSES growth and sustainability unit increase in $X_{7}$ (managerial constraints) leads to a 0.063 increasein MSEs growth and sustainability and a unit increase in $\mathrm{X}_{8 \text { (entrepreneurial constraint) }}$ leads to 0.184 decreasein MSEs growth and sustainability. Inferences can therefore be made that $\mathrm{x}_{1}$ $\mathrm{x}_{8}$ determines MSEs growth and sustainability

From the regression findings, the substitution of the equation (2) becomes:

$$
\mathrm{Y}=5.330-.0 .040 \mathrm{x}_{1}-.0 .147 \mathrm{x}_{2}-.0 .013 \mathrm{x}_{3}-0.136 \mathrm{x}_{4}-0.414 \mathrm{x}_{5}-0.135 \mathrm{x}_{6}+0.063 \mathrm{x}_{7}-0.184 \mathrm{x}_{8}
$$

Where $\mathrm{Y}$ is the dependent variable (MSEs growth and sustainability) $\mathrm{X}_{1}-\mathrm{X}_{8}$ arepredictors. According to the equation, taking all factors constant at zero, MSEs Growth and sustainability will be 5.330 . From the results, $\mathrm{x}_{5}$ (marketing constraint) as a component of MSEs growth and sustainability contributes most to the Growth and sustainability of enterprises, which has the greatest $t$ - value of 5.329, while $\mathrm{x}_{3 \text { (technological constraint) }}$ contributes the least, which has the smallest $t-$ value of 0.302 .

\subsection{Hypothesis Testing}

Table 8. Test of hypothesis.

\begin{tabular}{|c|c|c|c|}
\hline Determinants of MSEs growth and sustainability & Sig & P-Values & Decision \\
\hline Political - legal factors (x1) & 0.499 & $\mathrm{P}=0.499, \mathrm{p}>.05$ & $\mathrm{H}_{11}$ is rejected \\
\hline Working premise factors(x2) & $0.001 * *$ & $\mathrm{P}=.001, \mathrm{p}<.05$ & $\mathrm{H}_{12}$ is accepted \\
\hline Technological factors $(\mathrm{x} 3)$ & 0.763 & $\mathrm{P}=0.763, \mathrm{p}>.05$ & $\mathrm{H}_{13}$ is rejected \\
\hline Infrastructural factors $(\mathrm{x} 4)$ & $0.000 * *$ & $\mathrm{P}=0.000, \mathrm{p}<.05$ & $\mathrm{H}_{14}$ is accepted \\
\hline Marketing factors (x5) & $0.000 * *$ & $\mathrm{P}=0.000, \mathrm{p}<.05$ & $\mathrm{H}_{15}$ is accepted \\
\hline Financial factors (x6) & $0.025 * *$ & $\mathrm{P}=0.025, \mathrm{p}<.05$ & $\mathrm{H}_{16}$ is accepted \\
\hline Managerial factors $(\mathrm{x} 7)$ & 0.430 & $\mathrm{P}=0.430, \mathrm{p}>.05$ & $\mathrm{H}_{17}$ is rejected \\
\hline
\end{tabular}

** Significance $(\mathrm{p}<5 \%$ or 0.05$)$ 
Explanation Hypothesis testing

'Hypothesis-1Political - legal factors $\left(\mathrm{x}_{1}\right)$ ) has no a significant impact on entrepreneurial growth and sustainability $(\mathrm{P}=0.499, \mathrm{P}>0.05)$. Hence the hypothesis which stated as a Political - legal factors $\left(\mathrm{x}_{1}\right)$ has a significant impact on entrepreneurial growth and sustainability of Wolaita and Dawuro zones was rejected.

'Hypothesis-2Findings also indicated that the working premise factors $\left(\mathrm{x}_{2}\right)$ has a significant impact on the entrepreneurial growth and sustainability $(\mathrm{P}=0.001, \mathrm{P}<$ $0.05)$. Thus the hypothesis that Working premise factors has a significant impact entrepreneurial growth and sustainability of Wolaita and Dawuro zones was accepted.

'Hypothesis- $_{3}$ In addition, findings revealed that technological factors (x3) has no a significant impact on entrepreneurial growth and sustainability $(\mathrm{P}=0.763, \mathrm{P}>$ 0.05). Hence the hypothesis which stated as a technological factor has a significant impact on entrepreneurial growth and sustainability of Wolaita and Dawuro zones was rejected.

'Hypothesis- $_{4}$ Findings indicated that Infrastructural factors has a significant impact on entrepreneurial growth and sustainability $(\mathrm{P}=0.000, \mathrm{P}<0.05)$. Thus the hypothesis that an Infrastructure factor has a significant impact on the entrepreneurial growth and sustainability of Wolaita and Dawuro zones was accepted.

'Hypothesis- ${ }_{5}$ Findings indicated that Marketing factors has a significant impact on entrepreneurial growth and sustainability $(\mathrm{P}=0.000, \mathrm{P}<0.05)$. Thus the hypothesis that marketing factors has a significant impact on the entrepreneurial growth and sustainability of Wolaita and Dawuro zones was accepted.

'Hypothesis- ${ }_{6}$ Findings indicated that financial factors has a significant impact on entrepreneurial growth and sustainability $(\mathrm{P}=0.025, \mathrm{P}<0.05)$. Thus the hypothesis that a financial factor has a significant impact on the entrepreneurial growth and sustainability of Wolaita and Dawuro zones was accepted.

'Hypothesis- 7 findings revealed that Managerial factors has no a significant impact on entrepreneurial growth and sustainability $(\mathrm{P}=0.430, \mathrm{P}>0.05)$. Hence the hypothesis which stated as a Managerial factors has a significant impact on entrepreneurial growth and sustainability of Wolaita and Dawuro zones was rejected.

Hypothesis- 8 Findings indicated that an entrepreneurial factor has a significant impact on the entrepreneurial growth and sustainability of Wolaita and Dauwro zones. Thus the hypothesis which stated as an entrepreneurial factors has a significant impact on entrepreneurial growth and sustainability was accepted because of $\mathrm{P}=.007, \mathrm{p}<.05$.

To summarize the hypothesis testing, among eight determinant variables that affect entrepreneurial growth and sustainability of Wolaita and Dauwro zones. Five factors were statistically significant and three of them were statistically not significant at given level but this doesn't mean they have no influence on entrepreneurial growth and sustainability.

\section{Conclusion and Recommendations}

\subsection{Conclusion}

These researchers were carried out in Wolaita and Dawuro Zones with aim of critically investigating the factors affecting the growth and sustainability of MSE operators engaged in manufacturing, construction, trade, service and urban agriculture sectors. Based on the objectives and findings of the study, the researchers tried to conclude the study as follows:-

As indicated in chapter four discussion parts, more than 339 MSE operators participated in this study. As shown in back ground information of sample respondents, $75 \%$ were under age group category of 35-50 years and youth constituted only 2.62 . From total respondents, $66.37 \%$ were male remaining were female. As indicated in discussion part, the higher education graduates (first degree holders were $7.99 \%$ and more than $52 \%$ were primary and secondary school completed. Among all sample business venture owners, more than $50 \%$ were engaged in other activities (out of five development sectors). Enterprises included in this study created 1,681 job opportunities to their members. The researchers used factor analysis to reduce invalid variables from further analysis and unloaded variables ignored from further analysis.

Internal and external constraints that are currently affecting the MSEs growth and sustainability in the Wolaita and Dawuro zones include management, entrepreneurial, financial, marketing, working premise, infrastructural, technological and political-legal factors. The managerial and entrepreneurial factors are internal factor from eight study variables and their strength of association with MSEs growth and sustainability was weak. Shared variance of $13.10 \%$ and $19.89 \%$ respectively. External factors which are affecting the MSEs growth and sustainability in two Zones were financial, marketing, working premises, infrastructural, technological and political and legal constraints. Among six external MSEs growth and sustainability affecting constraints, marketing constraint is a major constraints which its strength of association with MSEs growth and sustainability is0.479and its it shared the variance of $22.94 \%$ andinfrastructural constraints shared less variance $(0.16 \%)$. The multiple regression model analysis result revealed that among eight study variables, 5 variables were statistically significant because their p-value is less than predetermined level and from previously formulated hypothesis testing 5 were accepted and three of the rejected because of their p-value more than significant level. To conclude the conclusion part, the Variables identified under this study predicted variance of $34 \%$ of MSEs growth and sustainability affecting factors in Wolaita and Dawuro Zones. Whereas $66 \%$ of the MSEs growth and sustainability affecting factors cannot be explained by this study variables alone.

\subsection{Recommendations}

Based on the finding results and conclusions of the study, 
the researchers forwarded the following recommendations:-

The prime concern of Ethiopian MSE strategy is to alleviate the urban youth unemployment problems and this requires a critical deep analysis of previous MSE scenario. The findings indicated that the operators who engaged in study area MSEs were passed youth age group which means only $2.66 \%$ were under age group of $18-35$ years so the MSE sector strategy objective which amid to create e jobs to unemployed youth did not ground rooted. The researchers recommend to responsible bodies to give a great attention at initial stage when structuring/organizing the groups in MSE because the currently existing enterprise in the study area are not youth and higher institution graduates targeted.

The findings showed that more than $50 \%$ of sample operators engaged out of five developmental sectors (manufacturing, construction trade, service and urban agriculture). This show that the MSE operators get credits and organized out of five MSE sectors without sound business plan. At its very beginning officials, MSE operators and responsible bodies should make a critical, deep business plan feasibility and future growth and sustainability evaluation. Future productivity and sustainability determined by attention given by initial stage because future is the function of the past,

As showed in the finding results of this study, eight study variables have association with MSEs growth and sustainability, controlling the adverse effect of those variables is very important. In GTP, MSEs are believed as control tools of poverty and unemployment in urban areas, the Wolaita and Dawuro Zones administrations and MSE owners would be responsible to create conducive working environment.

Internal MSEs growth and sustainability determinants (managerial \&entrepreneurial factors) are internal to MSE operators, they should increase their internal capability through continuous and periodic evaluation and mange this factors themselves.

Finally, the center of attention for this study was micro and small enterprises, medium and large enterprises did not included in this study. It is the researcher's view that the future researchers could therefore investigate the medium and large sectors. The internal and external constraints identified in this study were explained the variance of $34 \%$ of MSEs growth and sustainability affecting factors whereas the $66 \%$ variance of MSEs growth and sustainability affecting factors cannot be explained by this study, So it is advisable to the other potential researchers to conduct the research on the area of MSEs in the Wolita and Dawuro zones.

\section{Acknowledgements}

The authors thank Wolaita and Dawuro Zonemicro and small enterprise operators and Trade and industry department officials for providing all necessary data.

\section{References}

[1] Admasu, 2012. Factors Affecting the performance of Micro and Small Enterprises in Arada and Lideta Sub-Cities, Addis Ababa, Addis Ababa University, 1-6.

[2] Zemenu, and Mohammed, 2014. Determinants of Growth of Micro and Small Enterprises in Ethiopia (A Case of MSEs in Mekelle City, Tigray), International Journal of Advance Research in Computer Science and Management Studies 2, 149-157.

[3] FeMSEDA, 2015 Implementation, success and challenges of Micro and Small Enterprises (MSEs) development in Ethiopia Federal Micro and Small Enterprises Development Agency (FeMSEDA).

[4] Olabisi, S. Y., A. A. Olagbemi, and A. A. Atere. Factors Affecting Small-Scale Business performance In Informal Economy In Lagos State-Nigeria: A Gendered Based Analysis.

[5] Kinyua, A. N., Jan.2014. Factors Affecting the performance of Small and Medium Enterprises in the Jua Kali Sector InNakuru Town, Kenya, Journal of Business and Management 16.

[6] Kamunge, M. S., D. A. Njeru, and O. I. Tirimba, 2014. Factors Affecting the Growth and sustainability of Small and Micro Enterprises in Limuru Town Market of Kiambu County, f Kiambu County, f Kiambu County, f Kiambu County, International Journal of Scientific and Research Publications 4, ISSN 2250-3153.

[7] Tamiru, 2013. Problems and Constraints of Micro and Small Enterprises in Nefas silk- Lafto Sub City, 9.

[8] Berihu, Abebaw, and Biruk, 2014. Identifying Key Success Factors and Constraints in Ethiopia's Mse Development: An Exploratory Research, Ethiopian Development Research Institute: Addis Ababa, Ethiopia Research Report 18.

[9] Bereket, 2010. The Role of Micro and Small Enterprises in Employment Creation and Income Generation A Survey Study of Mekelle City, Tigray Region, Ethiopia, 14-15.

[10] Yamane, Taro. (1967). Statistics: An Introductory Analysis, 2nd Edition, New York: Harper and Row. 